\title{
PERFORMANCE ISSUES WITH CLOUD COMPUTING
}

\author{
Saurav Gupta \\ Department of Computer Science \\ Lovely Professional University, IN
}

\author{
Akash Kumar \\ Department of Computer Science \\ Lovely Professional University, IN
}

\author{
Kandibanda Sai Santhosh \\ Department of Computer Science \\ Lovely Professional University, IN
}

\begin{abstract}
Cloud computing is key for today's fast world. It serves across all the domains. Be it business, educational, public, or private sector, etc. Its application can be observed anywhere. Its overall concept and its analysis of services and model are presented here. Mainly cloud has 3 delivery models. Saas (Software as a service), Paas(Platform as a service), and Iaas (Infrastructure as a service). We explored these with their performances and interdependencies. Cloud adoption has its performance limitation and solutions to overcome these challenges are provided here. Also, cloud delivery models are discussed. Performance factors are very important for as a whole cloud computing success, where it adds its ideal cost of services, its reliability, and its scalability constitutes as its pillar factors. They require a lot of attentiveness and effort by the cloud computing providers and contributors, integrators, and service consumers
\end{abstract}

Keywords - Cloud computing, Cloud types, delivery model

\section{INTRODUCTION}

Nowadays, cloud computing is expedited to a destination with no comeback. Just a few cloud-computing services include Microsft Azure, Amazon EC2, and Google Apps, all of these ecosystems have faced some kind of outage or shutdowns at one point or another in the past, thereby affecting the businesses worldwide, especially those that depend on the cloud for their core businesses.

Now is the time to take a quick step at the critical challenges you might face while implementing and operating in the cloud.

- An application that fits the cloud

- Dealing with the performance issues

- Addressing the topological dependencies

- Monitoring consumption for each service

- Having a clear picture of resource consumption

Not all applications are suitable for the cloud. It is very important to identify the most suitable applications for migration and identify any potential problems. Create a checklist to ensure complete and successful migration of the cloud services.
If you are supervising application performance in the cloud, you need a topological map of service delivery across all nodes. Although cloud computing provides various benefits, performance issues can complicate or reduce the benefits.

The Cloud computing environment enables a new framework that transfers the physical location of computation and storage into the network to reduce operational and maintenance costs. While mobile or remote and rapid computing provides all-over access of users to services, cloud computing harnesses the vast storage, computing, and software infrastructure resources into a single virtualized infrastructure with everywhere presence.

While moving to the cloud, various businesses need to face the impact of moving from a primarily static to dynamic network architecture. Firewall, load balancing, and security services are still needed for the network architecture and its implementation

While transitioning from a resource-focused cost center to a business service-focused profit center, demands assessing the resource consumption. Unfortunately, the traditional chargeback and AMP tools cannot enable the business-aligned costing and chargeback paradigms. This indicated that you need to come up with a result of the well-defined solution to monitor consumption for every service across multiple applications and tiers

The coming sections of the paper are organized as follows. Performance measures are explained in section II. Diagnose presented in section III. The conclusion is given in section IV.

\section{PERFORMANCE MEASURES}

\section{A. Characteristics of performance measures}

Cloud has the following major measures of performance.

- $\quad$ SaaS performance measures are directly perceived by the user as business transaction response times and throughput, technical service reliability, and availability, and by the scalability of the applications 


\section{International Journal of Engineering Applied Sciences and Technology, 2021 \\ Vol. 6, Issue 4, ISSN No. 2455-2143, Pages 288-291 \\ Published Online August 2021 in IJEAST (http://www.ijeast.com)}

- PaaS performance measures are indirectly recognized by users and defined as technical transaction response times and throughput, technical service reliability, and availability, and the scalability of the middleware.

- Infrastructure-as-a-Service simply referred to as simply "IaaS," is a form of cloud computing that transports fundamental compute, network, and storage resources to consumers on request, over the internet or cloud, and on a pay-as-you-go basis principle. IaaS permits end-users to scale and shrink resources on an as-needed basis, shrinking the need for costly, up-front capital expenditures or unnecessary "owned" infrastructure, especially in the case of "uneven" workloads. Indifference to PaaS and SaaS (even newer computing models like containers and serverless), IaaS leverage the lowestlevel control of resources in the cloud on-demand basis. Its performance measures are defined as infrastructure resource performance, reliability, capacity, scalability, and availability.

- In general, characteristics of performance measures of the upper service layers depend on those characteristics in the underlying layers, e.g. SaaS layer scalability depends on IaaS layers capability and performance.

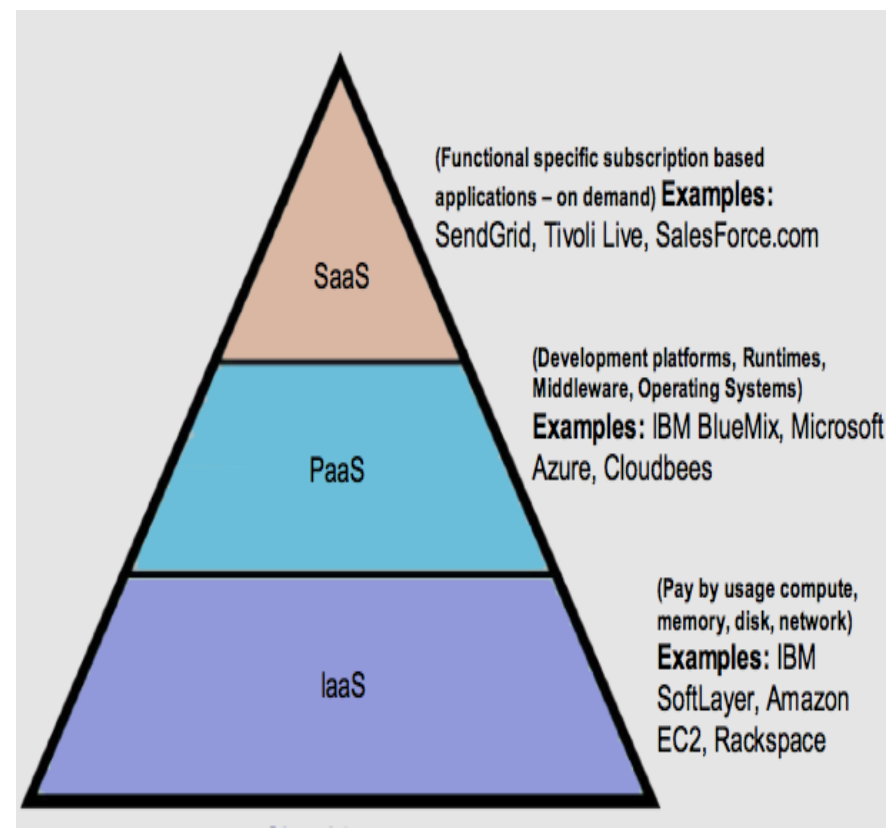

Fig 1. Cloud layers

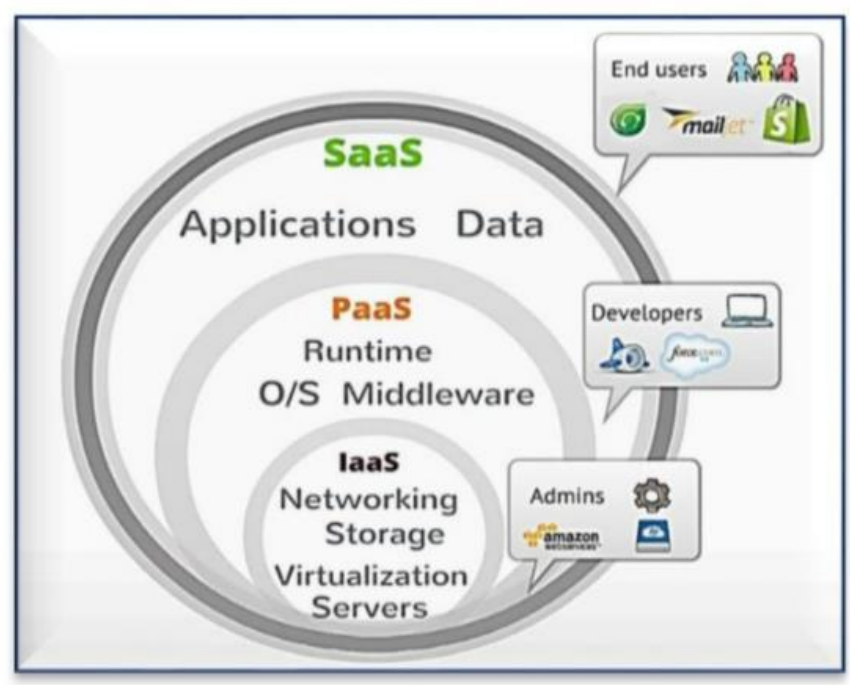

Fig 2. Cloud service layers

\section{B. Performance Aspects of a major obstacle in cloud adoption and growth}

The success of Cloud deployments is highly proportional to practicing holistic and systematic performance engineering and capacity management techniques.

A major part of the challenges for the adoption and growth of cloud computing is related to the basic performance things. Its governing factors are again these such as availability, performance, capacity, or scalability. Please refer to Figure 3 for the obstacles and opportunities details.

Following are the performance aspects in cloud adoption:

- Potential cloud solutions to solve these obstacles need to be carefully assessed for their authenticity in real-life situations

- Performance engineers need to get to the root of the technology transactions of underlying cloud services before advising cloud computing users and cloud computing providers for the cloud services and their applications.

- The degree to which cloud services can meet agreed with service-level requirements for performance availability, and scalability can be estimated by using performance modeling techniques or any modeling ways so that potential performance anti-patterns usability structure can be detected before they happen.

- In the absence of modern tooling for automated and self-driven monitoring, the automatic provisioning and usage-based costing facilities, rely mainly on fine-grained capacity management. Until more future 


\section{International Journal of Engineering Applied Sciences and Technology, 2021 \\ Vol. 6, Issue 4, ISSN No. 2455-2143, Pages 288-291 \\ Published Online August 2021 in IJEAST (http://www.ijeast.com)}

data collection, analysis, modeling, and forecasting are in

- $\quad$ Respective of modern tooling for automated and selfdriven monitoring, cloud computing users need to analyze their demand for capacity and their requirements for performance. In their contract with cloud computing providers, users should always take a bottom-line approach to accurately formulate their service-level requirements timely

\begin{tabular}{|c|c|c|}
\hline & Obstacle & Opportunity \\
\hline 1 & $\begin{array}{l}\text { Availability of } \\
\text { Service }\end{array}$ & $\begin{array}{l}\text { Ensure Business Continuity by defining firm SLAs and } \\
\text { Fault tolerance through multiple cloud providers in place. } \\
\text { Use Elasticity (scale resources both up and down as } \\
\text { needed) to Defend Against Distributed Denial of Service } \\
\text { (DDoS) attacks }\end{array}$ \\
\hline 2 & Data Lock-In & $\begin{array}{l}\text { Standardize APIs; Make compatible software available to } \\
\text { enable Surge Computing }\end{array}$ \\
\hline 3 & $\begin{array}{l}\text { Data } \\
\text { Confidentiality } \\
\text { and Audit-ability }\end{array}$ & $\begin{array}{l}\text { Deploy Encryption, VLANs, and Firewalls; } \\
\text { Accommodate National Laws via Geographical Data } \\
\text { Storage }\end{array}$ \\
\hline 4 & $\begin{array}{l}\text { Data Transfer } \\
\text { Bottlenecks }\end{array}$ & $\begin{array}{l}\text { FedExing Disks; Lower WAN Router Costs; Higher } \\
\text { Bandwidth LAN Switches } \\
\text { Tools which can deliver high-speed transfers in, out and } \\
\text { across the cloud with scale-out transfer capacity on web, } \\
\text { mobile or embedded in application itself. }\end{array}$ \\
\hline 5 & $\begin{array}{l}\text { Performance } \\
\text { Unpredictability }\end{array}$ & $\begin{array}{l}\text { Improved Virtual Machine Support; Flash Memory; Gang } \\
\text { Scheduling VMs for HPC apps Performance } \\
\text { A number of as-a-service performance predictability } \\
\text { solutions are in place and growing for Holistic Cloud } \\
\text { performance engineering and capacity management }\end{array}$ \\
\hline 6 & Scalable Storage & $\begin{array}{l}\text { Invent Scalable Store } \\
\text { Cloud solutions for high-performance, scalable storage- } \\
\text { virtualization to facilitate growth and innovation at lower } \\
\text { operational costs. }\end{array}$ \\
\hline 7 & $\begin{array}{l}\text { Bugs in Large- } \\
\text { Scale Distributed } \\
\text { Systems }\end{array}$ & Invent Debugger that relies on Distributed VMs \\
\hline 8 & Scaling Quickly & $\begin{array}{l}\text { Invent Auto-Scalar that relies on Machine Learning; } \\
\text { Snapshots to encourage Cloud Computing } \\
\text { Conservationism } \\
\text { A number of as-a-service solutions are in this research } \\
\text { focus area to address the dynamic scaling (scale up, out } \\
\text { and down) needs }\end{array}$ \\
\hline 9 & $\begin{array}{l}\text { Reputation Fate } \\
\text { Sharing }\end{array}$ & Offer reputation-guarding services like those for email \\
\hline 10 & $\begin{array}{l}\text { Software } \\
\text { Licensing }\end{array}$ & Pay-for-use licenses; Bulk use sales \\
\hline
\end{tabular}

Fig. 3. Top Ten Obstacles and Opportunities for Adoption and Growth of Cloud Computing - Performance view ( Reference: A Berkeley View of Cloud Computing )

\section{HOW TO DIAGNOSE PERFORMANCE ISSUES}

Cloud performance is very networked complex because it's a complex distributed system at the end of the day. However, follow the five diagnoses steps below to find and fix the main root causes of the facing issues. If you can reproduce performance issues at a particular step, don't stop there, just keep moving. You can have more than one issue affecting performance belongs to different levels check. So It is not like to get stop if you failed in steps before. Just follow the 1-5 steps and keep a log of the issues.

1. Examine the infrastructure that reinforces the workloads, both application and data

a. Using system observation and log analysis tools, you can determine CPU and storage consumption, which are the most likely culprits

b. Many Information Technology pros using clouds crash to assign more CPUs and storage as required as an application's and database's size expand over time. Although you would suppose that a public cloud automatically expands to meet your needs, that's not the occasion. You need to structure and provision more servers to handle to additional workload before they are needed

\section{Observed and judge the applications themselves}

a. Many monitoring tools can peer into the application system directly, and I strongly recommend that you use one or more of them to help you out.

b. Applications are the foe for poor performance almost as often as the infrastructure is because they may not have been refactored or changed to used cloudnative features. Thus, they can act very inefficiently at using the infrastructure component, which falsely puts the performance blame on the infrastructure for no reason.

3. Look at other less likely root causes of performance issues, which you think is not on the priority

a. Now it's time to check other components which may not look like primary issue sources. Check the security system: Encryption services can saturate storage and compute parts. Check the governance services - even the monitoring services that will tell you about performance downs in the first place. I've found that all such helping tools can oversaturate the infrastructure performance.

4. Proceed to the network, including connection, configuration, and bandwidth checks inside and outside the cloud

a. Because users have taken public cloud services over the open internet, you're often competing with lots of other packets during 


\section{International Journal of Engineering Applied Sciences and Technology, 2021 \\ Vol. 6, Issue 4, ISSN No. 2455-2143, Pages 288-291 \\ Published Online August 2021 in IJEAST (http://www.ijeast.com)}

data transmission. To observe if that's a cause of your poor performance, perform ping tests over the network, as well as data movement up and down, using tests that estimate what's transmitted and used by the cloud-based workloads.

\section{Look end to end the users' browsers and computers}

a. Finally, there are often issues with the users' browsers that interact with the cloud-based application, which needs end-to-end debugging.

b. I've found malware, encryption issues, and basically, all of the things that can go wrong with Windows PCs and Macs can make the cloud performance down at the client-side. Have technical support guidelines run those down if the first four steps come up clean. Belong fig 4 represents the common problem faced by an organization.

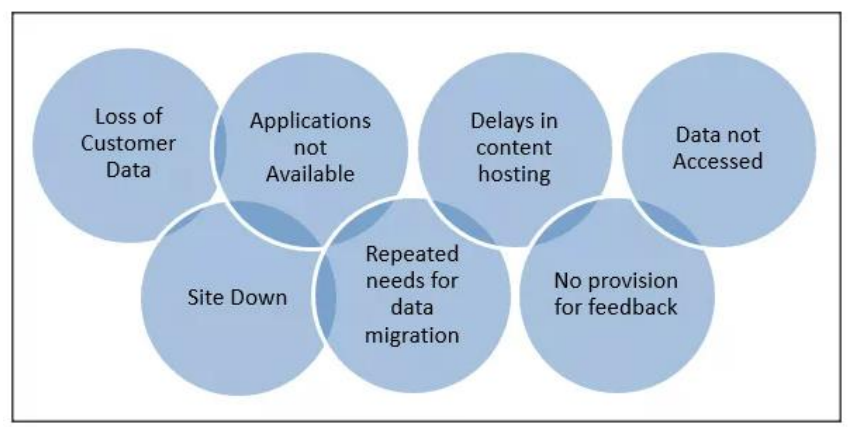

Fig. 4. Problems faced by Organizations with Cloud computing.

\section{CONCLUSION}

The research aimed to answer the research questions related to the perception of the issues in the cloud and how cloud computing systems to end-users are getting impacted with common use-case failures. We talked about what are the performance characteristics and how we can measure them for different cloud computing mapping. If we follow the 10 Obstacles and opportunities for growth for performance computing we can make the system more reliable without impacting the service and quality of the cloud. We researched the 5 methods by which we can diagnose the performance issues and the problems faced by Organizations with Cloud computing.

This paper has highlighted the consequence of cloud computing to manage the computing needs of today's complex business scenarios, its advantages such as the shift from CapEx to OpEx, elasticity, and adaptability, pay-per-use, on-demand, resiliency, workload action, and multi-tenancy. Also elaborated the different cloud computing perspectives, highlighting performance engineering with various cloud models, and detailed performance considerations for the cloud and its application. The standard cloud service delivery models, namely SaaS, PaaS, and IaaS, have their performance challenges as well as inter-dependencies for implementation, and to performance of one model to another.

In summary, the challenge presented for performance is significant and discipline needs to continue to innovate to meet that challenge. Industry watchers (such as Gartner) are predicting that Performance Engineering becomes even more critical to the success of the Cloud-based Information Technology industry.

\section{REFERENCE}

[1] Aswathi Vandna P., Nandhini A., Saravana "An Overview of Performance Issues in Cloud Computing", IJERT Vol. 2 Issue 9, September - 2013.

[2] Bhaskar Prasad Rimal, Enumi Choi, Ian Lumb, "A taxonomy and survey of the cloud computing systems", 5th International Joint Conference in INC, IMS and IDC, 978-0- 7695-3769-6/09, 2009, pp 44-51

[3] Yilei Zhang, Zibin Zheng and Michael R. Lyu, "BFTCloud: A Byzantine Fault Tolerance Framework for the Voluntary-Resource Cloud Computing", 2011 IEEE 4th International Conference on Cloud Computing.

[4] L. Lamport, R. Shostak, and M. Pease, "The Byzantine generals problem," ACM Transactions on Programming Languages and the Systems (TOPLAS), vol. 4, no. 3, pp. 382-401, 1982.

[5] Saurabh Kumar Garg, Steve Versteeg, and Rajkumar Buyya, "SMICloud: A Framework for the Comparing and Ranking Cloud Services", 2011 Fourth IEEE International Conference on Utility and Cloud Computing.

[6] C.S.M.I.C. (CSMIC), -SMI Framework,\| URL:http://betawww.cloudcommons.com/servicemeasure me ntindex.

[7] J. Varia, Cloud Computing: Principles and Paradigms. Wiley Press, 2011, ch. 18: Best Practices in Architecting Cloud Applications in the AWS Cloud, pp. 459-490.

[8] David Escalnte and Andrew J. Korty, -Cloud Services: Policy, and its Assessmentl, EDUCAUSE Review, Vol. 46, July/August 2011 